\title{
Colostro bovino: muito além das imunoglobulinas
}

Viviani Gomes ${ }^{[]^{a}}$, Camila Costa Baccili[b], Camila Cecilia Martin ${ }^{[b]}$, Jean Silva Ramos ${ }^{[b]}$, Natália Sobreira Basqueira ${ }^{[b]}$, Karen Nascimento Silva ${ }^{[b]}$, Karina Medici Madureira ${ }^{[c]}$

\begin{abstract}
[a] Professora do Departamento de Clínica Médica, Faculdade de Medicina Veterinária e Zootecnia, Universidade de São Paulo (USP), São Paulo, SP, Brasil

[b] Discentes do Programa de Pós-Graduação em Clínica Médica, Faculdade de Medicina Veterinária e Zootecnia, Universidade de São Paulo (USP), São Paulo, SP, Brasil

[c] Professora do Departamento de Anatomia, Patologia e Clínicas, Escola de Medicina Veterinária e Zootecnia, Universidade Federal da Bahia (UFB), Bahia, BA, Brasil
\end{abstract}

*Autor correspondente

e-mail: viviani.gomes@usp.br

\section{Introdução}

A adaptabilidade do recém-nascido às condições ambientais pós-nascimento é crítica, e geralmente está associada aos elevados índices de morbidade e mortalidade. A morbidade por diarreia neonatal e broncopneumonias em bezerras é ao redor de $23 \%$ e $21,9 \%$, respectivamente, entre o nascimento e desmame. A taxa de mortalidade observada na fase de aleitamento é de aproximadamente 3,5\%, observando-se pico máximo de mortes ao redor dos 19 dias de vida. A falha na transferência de imunidade passiva (Proteína total $\leq 5,7 \mathrm{~g} / \mathrm{dL}$ ) está associada com a precocidade e aumento da incidência de broncopneumonias (Windeyer et al., 2014).

0 principal limitante para a adaptação dos bezerros ao ambiente extrauterino é a imaturidade funcional e regulatória dos órgãos. Os bezerros nascem hipogamaglobulinêmicos e possuem sistema imune adaptativo näive, além de imunossuprimidos em função da interação entre os hormônios e citocinas presentes no ambiente materno-fetal. Apesar de apresentarem todos os componentes essenciais, a montagem da resposta imune pósnatal inicialmente é lenta e de baixa intensidade, devido à imaturidade funcional das células imunes. Sendo assim, a transferência de imunidade passiva é essencial para a proteção dos bezerros contra as doenças nessa fase crítica da vida (Barrington e Parrish, 2001; Chase et al., 2008).

0 colostro representa uma importante fonte de imunoglobulinas, entretanto as Igs não são os únicos constituintes transferidos por imunidade passiva. Além das Igs, o colostro contém citocinas 
e um grande número de leucócitos maternos, que contribuem coletivamente para a imunoproteção do neonato (Gonzalez e Santos, 2017). O papel das Igs na proteção dos recém-nascidos contra os microorganimos tem sido bem documentado, entretanto a função das células maternas e seus produtos (citocinas) ainda é pouco compreendida. Além da transferência de fatores imunes, a secreção mamária é uma importante fonte de Lactobacillus e Bifidobacterium. Estes microrganismos são fundamentais para o desenvolvimento da imunidade de mucosas e saúde intestinal.

Neste contexto, o objetivo desta revisão é trazer informações atualizadas sobre o papel dos fatores imunes do colostro, além das imunoglobulinas (Igs), que atuam na proteção direta ou indireta dos bezerros recém-nascidos.

\section{Imunidade ao início da vida}

Fenômenos ocorridos durante a gestação influenciarão ao nascumento o padrão imune dos bezerros recém-nascidos.

0 ambiente feto-placentário é reconhecido pelo sistema imune da mãe como não-próprio, o que desencadearia a produção das citocinas TNF- $\beta$ e IFN- $\gamma$ pelos macrófagos (M1), responsáveis pela diferenciação das células Th0 em Th1 (imunidade celular). Estas citocinas exercem efeitos deletérios induzindo inflamação e necrose nas células dos trofoblastos. Para bloquear esta via imune, macrófagos (M2) produzem as citocinas IL-4 e IL10, que estimulam a diferenciação das células Th0 em Th2 (imunidade humoral), que promovem a proliferação e diferenciação das células dos trofoblastos e placentação. Outros hormônios como a prostaglandina E2, progesterona, além de mais citocinas IL-4 e IL-10, serão produzidos pela placenta. Acredita-se que as células inflamatórias estão ativadas na gestação como mecanismo compensatório da supressão da resposta celular Th1, exceto as células natural killer (NK), inibidas pelo seu potencial em causar citotoxidade aos trofoblastos (Figura 1). Sendo assim, a manutenção da gestação é dependente da modulação da resposta imune materna e fetal de Th1 para Th2. 0 efeito cumulativo de estrógeno e cortisol materno também suprime a resposta fetal do tipo Th1 (Morein et al., 2002; Sacks et al., 1999; Wegmann et al., 1993).

As vacas e outros ruminantes possuem placenta sindesmocorial, representada pela formação de sincício entre oendométrio materno eotrofectoderma fetal, que separa o sangue da mãe e do feto. Este sistema é impermeável às macromoléculas para prevenir a transmissão vertical de microorganismos. Em contrapartida, os ACs maternos também não serão transferidos passivamente durante a gestação (Barrington e Parrish, 2001; Chase et al., 2008).

0 cortisol no ambiente feto-placentário, ao redor da parição, afeta a resposta imune inata dos recémnascidos. 0 cortisol promove o aumento do fator estimulador de colônias granulocíticas, liberação de neutrófilos da reserva medular e a diminuição da expressão da molécula de adesão L-selectina (CD62L) em granulócitos. Estes fenômenos proporcionam o influxo de neutrófilos para os vasos sanguíneos, associado à diminuição do efluxo dessas células para os tecidos. A atividade funcional dos granulócitos também estará reduzida, devido à diminuição da produção intracelular de espécies reativas do oxigênio (ERO's) após a fagocitose. 0 cortisol também afeta a distribuição dos linfócitos no organismo, observandose migração de linfócitos do sangue para os tecidos linfóides (periferia). Nesta fase, a capacidade de expansão clonal dos linfócitos estará reduzida (Costa et al., 2017; Tornquist e Rigas, 2010).

Figura 1 - Modulação da resposta imune no ambiente fetoplacentário.

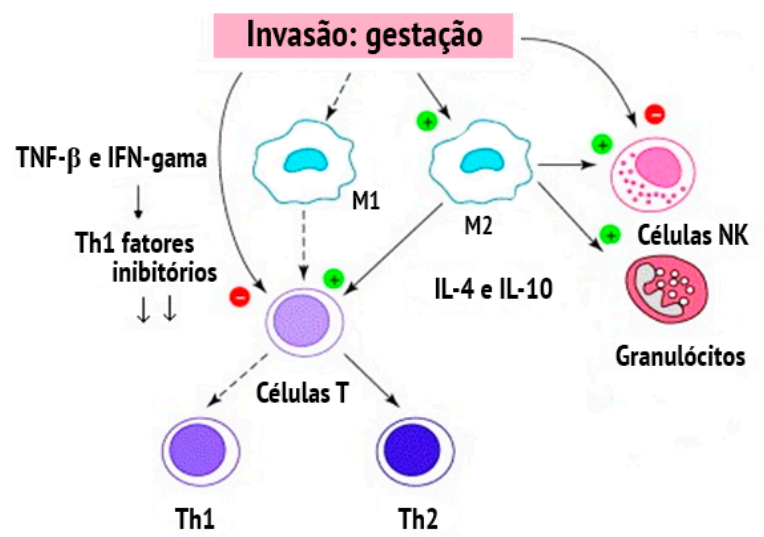

Nota: Adaptado de Sacks et al., 1999. 
Em geral, o sistema imune dos bezerros recém-nascidos está completamente formado ao nascimento, porém esses animais apresentam sistema imune enfraquecido devido ao perfil hormonal no ambiente feto-placentário e imaturidade do sistema imune adaptativo (näive) (Quadro 1).

A colonização dos recém-nascidos é intensa a partir do nascimento, e requer respostas imunes extremamente reguladas para tolerar os microorganismos da microbiota (comensais/ simbióticos), ao mesmo tempo que necessita reconhecer e destruir os agentes patobióticos.

Ao início da vida, os recém-nascidos montam resposta imune adquirida de forma lenta e gradual. Resumidamente, as células sentinelas capturam os antígenos e migram para os órgãos linfóides secundários com o objetivo de estimular os $\mathrm{T}$ virgens, que produzem diferentes perfis de citocinas, responsáveis pela modulação da resposta imune adaptativa Th1 e Th2 (Barrington e Parrish, 2001; Chase et al., 2008) (Figura 2).

Quadro 1 - Perfil imune dos bezerros recém-nascidos ao nascimento

\begin{tabular}{|c|c|}
\hline Diminuição da Resposta Imune Inata & Resposta Imune Adquirida \\
\hline$\downarrow$ Atividade do sistema complemento & Hipogamaglobulinemia \\
$\downarrow$ Atividade dos neutrófilos e macrófagos & Não possuem memória de células T e B \\
$\downarrow$ células dendríticas & $\downarrow$ expressão de moléculas de MHCII \\
$\downarrow$ Atividade células natural killer & $\downarrow$ Apresentação de antígenos para células T \\
$\downarrow$ Produção de Interferon & $\downarrow$ Resposta funcional de linfócitos \\
& Resposta Imune predominante Th2 \\
\hline
\end{tabular}

Nota: adaptado de Chase et al., 2008.

Figura 2 - Desenvolvimento da resposta imune adquirida em recém-nascidos mediante exposição antigênica pós-natal

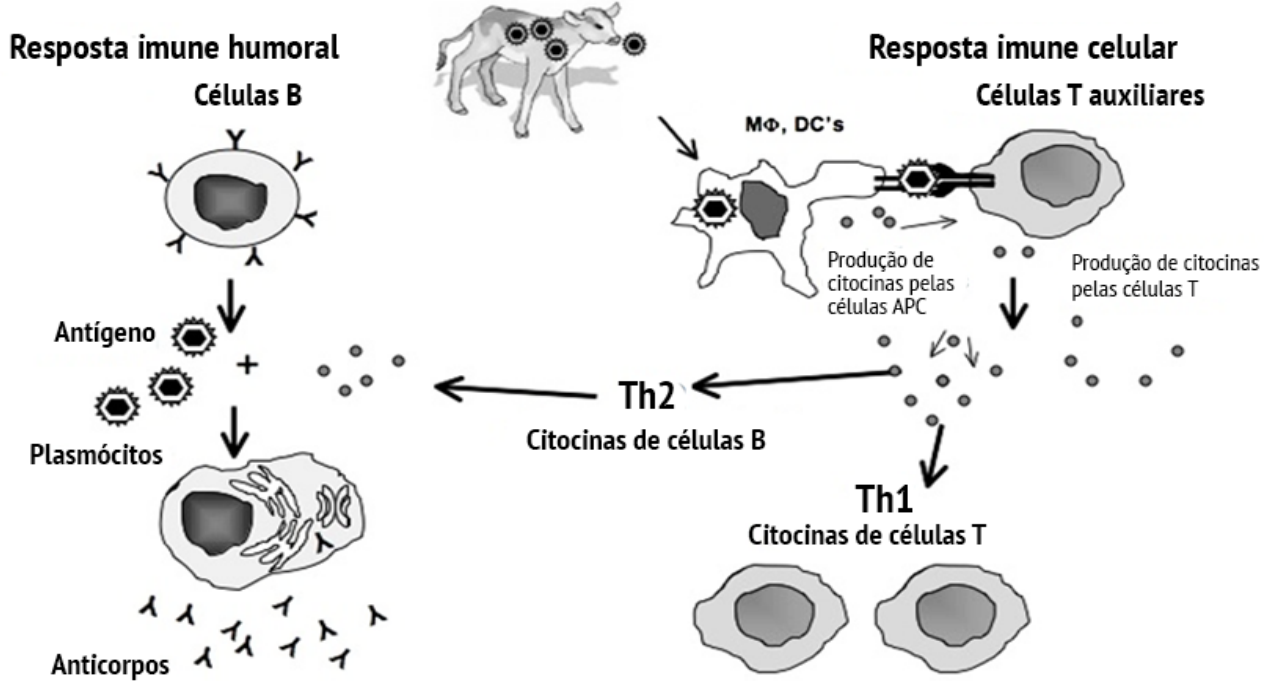




\section{Papel do colostro na defesa dos bezerros recém-nascidos}

A palavra "colostro" parece ter sido usada pela primeira vez no século XVI (1570 - 1580, do latim colostrum). 0 reconhecimento da importância das imunoglobulinas do colostro para os mamíferos iniciou-se no final do século XIX, e os estudos sobre o papel das imunoglobulinas nos mecanismos da defesa contra patógenos foi praticamente elucidado no século XX (Baumrucker e Bruckmaier, 2014). Apesar da IgG ter sido a protagonista das pesquisas no século passado, a transferência das células derivadas do colostro, assim como os seus subprodutos, foi cogitada na década de 70 . Em geral, os estudos vêm demonstrando que as imunoglobulinas atuam em conjunto com os demais componentes imunes do colostro para a proteção dos recém-nascidos.

\section{IgG: clássica transferência de imunidade passiva}

O colostro bovino contém aproximadamente $90 \%$ de IgG, 5\% de IgA e 7\% de IgM. A concentração de Igs das classes $\mathrm{G}, \mathrm{A}$ e $\mathrm{M}$ presentes no colostro de vacas Holandesas é ao redor de 10.078, 413,8 e 625 $\mathrm{mg} / \mathrm{dL}$, respectivamente (Gomes, 2008).

O predomínio de IgG no colostro bovino está de acordo com a necessidade de proteção sistêmica dos bezerros recém-nascidos, considerando-se que não há transferência passiva de anticorpos maternos no período fetal. A transferência passiva de IgG pela ingestão de colostro é possibilitada pela permeabilidade da mucosa intestinal dos ruminantes às macromoléculas nas primeiras 18 horas de vida. A principal função da IgG é a neutralização e a opsonização dos microorganismos, além da sua participação na citotoxicidade celular dependente de anticorpos.

\section{Células: os componentes esquecidos do colostro}

Os leucócitos foram observados pela primeira vez no colostro humano por Alexander Donné (1844) apud Mandyla et al. (1982).
O colostro bovino contém entre $1 \times 10^{6}$ e $2,5 \times$ $10^{6}$ células somáticas $/ \mathrm{mL}$, dentre as quais $32 \%$ são viáveis (Lieber-Tenório et al., 2002; Silva, 2014). 0 predomínio celular é de mononucleares, especialmente monócitos e células epiteliais (69,5\%), além de linfócitos (16,4\%), neutrófilos $(13,3 \%)$ e eosinófilos $(0,27 \%)$ (Gomes et al., 2011). A avaliação funcional destas células é limitada pela dificuldade no seu isolamento, devido à abundante quantidade de debris celulares, gordura, proteínas e partículas autofluorescentes (Gomes et al., 2014).

A passagem das células derivadas do colostro pelo epitélio intestinal foi comprovada em leitões (Tuboly et al., 1988; Williams, 1993), ovinos (Sheldrake e Husband, 1985; Tuboly et al., 1994) e bezerros (Aldridge et al., 1998; Liebler-Tenorio et al., 2002; Reber et al., 2006). Em seguida, estas células migram para o sangue (pico entre $12 \mathrm{e}$ 24h) para colonizar a Placa de Peyer e linfonodos (Aldridge et al., 1998; Liebler-Tenorio et al., 2002; Reber et al., 2006) (Figura 3).

É consensual que as células maternas derivadas do colostro contribuem nos mecanismos de resposta imune inata e específica dos bezerros recém-nascidos.

A atividade direta das células do colostro na eliminação de enteropatógenos foi demonstrada por Riedel-Caspari (1993). Este autor administrou $10^{9}$ unidades formadoras de colônias (UFC) de Escherichia coli enteropatogênica (EPEC), por via oral, para 20 bezerros em até três horas pósnascimento. Em seguida, os bezerros foram distribuídos em dois grupos: $\mathrm{COL}+$ recebeu pool de colostro com células $(\mathrm{n}=10)$; COL- recebeu colostro acelular. 0 número de UFC excretadas foi menor nos bezerros COL+ na primeira semana de vida, além disso, os bezerros que receberam colostro com células negativaram antes que os animais COLAs concentrações de IgA e IgM específicos contra Escherichia coli no soro do COL+ também foram maiores do que aquelas do COL-.

Novo et al. (2017) acompanharam o perfil sanitário e hematológico de 20 bezerras Holandesas criadas em alojamentos individuais, das quais 10 receberam colostro fresco com células $(\mathrm{COL}+)$ e 10 receberam colostro congelado sem células viáveis (COL-). Este estudo demonstrou que as bezerras apresentaram prevalências de diarreias 
semelhantes em diferentes momentos do estudo, entretanto a doença foi mais intensa no grupo COL-. As bezerras COL- apresentaram maior frequência de escore fecal 3 (classificação de 0 a 3), maior temperatura retal, maior frequência respiratória e anemia associada a menores teores de ferro, especialmente nos momentos coincidentes com os picos de diarreia (D7-D14).

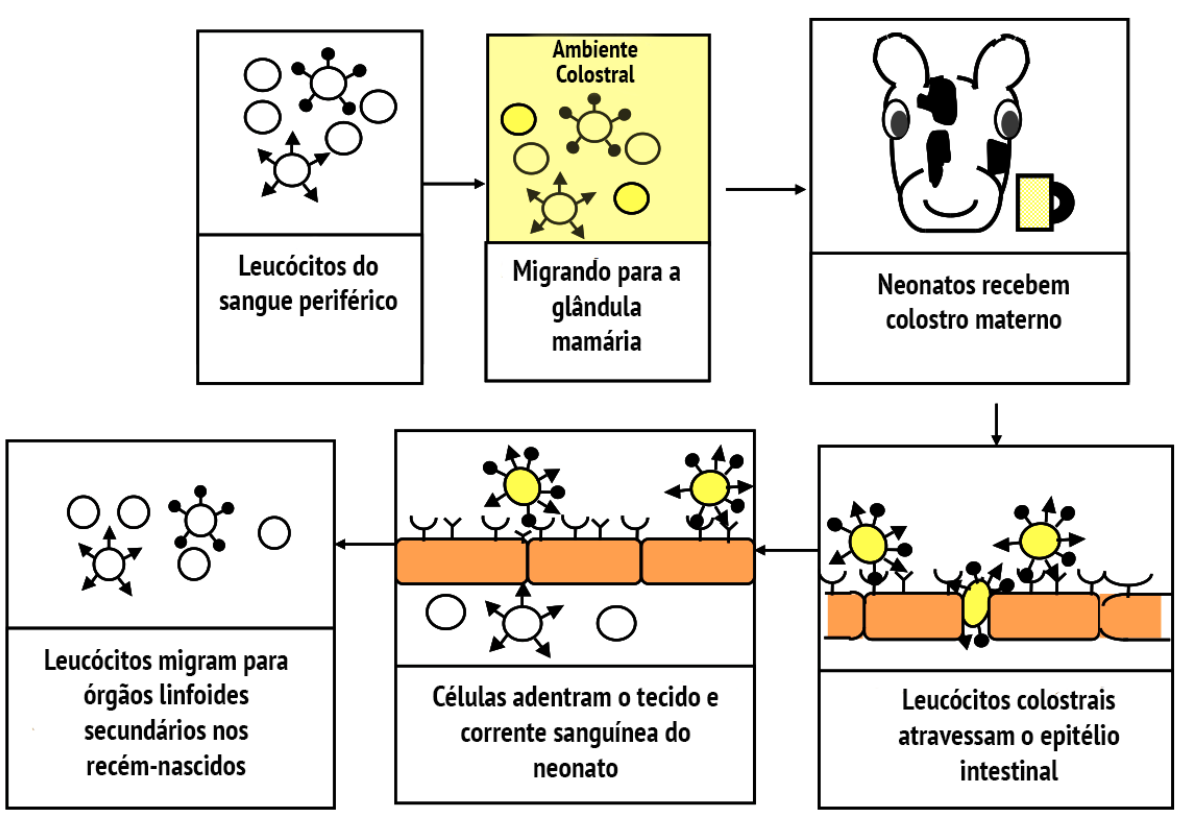

Nota: Adaptado de Reber et al., 2006.

Figura 3 - Migração das células maternas pelo epitélio intestinal dos recém-nascidos bovinos.

Os achados clínicos descritos nos estudos experimental e a campo são condizentes com o perfil celular relatado para as bezerras COL-. As células mononucleares sanguíneas destes animais apresentam maior expressão de receptores indicativos de inflamação (CD11a, CD11c, CD43 e CD62L) (Costa et al., 2017; Reber et al., 2008a; Reber et al., 2008b;). Cluster of differentiation (CD) é o conjunto de moléculas marcadoras de superfície celular usada para diferenciar variados tipos de células. 0 receptor CD11 (integrina) é encontrado nos leucócitos e exerce papel-chave na ligação dos leucócitos ao endotélio vascular durante o processo de migração aos tecidos; o receptor CD43 é uma estrutura antiadesiva expressa nos leucócitos, exceto células B em repouso; o receptor CD 62L é uma molécula de adesão, encontrada nas células B e
T, monócitos e células NK, que atua no processo de rolamento dos leucócitos no endotélio (Murphy et al., 2010).

Em relação ao sistema imune inato, os granulócitos das bezerras COL+ são mais ágeis no processo de migração ao intestino quando expostas naturalmente aos microrganismos causadores das diarreias. A atividade microbicida dos granulócitos contra Staphylococcus aureus e Escherichia coli, mensurada pela produção intracelular de ERO's, também é maior nas bezerras $\mathrm{COL}+$. Sendo assim, pode-se afirmar que as bezerras $\mathrm{COL}+$ desenvolvem resposta imune inata mais rápida e eficiente contra os patógenos após exposição natural aos microrganismos no período pós-natal. Ao contrário, as bezerras COL- montam lentamente a resposta imune inata, que resulta em infecção persistente (Costa et al., 2017). 
Em relação ao sistema imune específico, os bezerros amamentados com colostro celular são precoces no processo de amadurecimento dos linfócitos näive.

Os linfócitos dos bezerros COL+ apresentam maior expressão dos marcadores CD25, CD26 e CD172a, em relação ao COL- (Langel et al., 2015; Reber et al., 2006; Reber et al., 2008a; Reber et al., 2008b;). 0 receptor CD25 é um receptor de interleucina expresso apenas pelas células $\mathrm{T}$, células B e monócitos após o reconhecimento antígenoespecífico; e o receptor CD26 é um receptor de células $\mathrm{T}$, especialmente linfócitos auxiliares de memória.

Os linfócitos dos bezerros COL+ apresentam maior atividade funcional caracterizada por maior taxa de proliferação e/ou produção de anticorpos após estimulação com antígenos (BVDV, Staphylococcus aureus, Escherichia coli), super antígenos e mitógenos, (concanavalina e SEB) (Donovan et al., 2007; Riedel-Caspari e Schmidt, 1991a; Riedel-Caspari e Schmidt, 1991b; Novo et al., 2017b).

\section{Citocinas: as proteínas que conectam os componentes do sistema imune}

O termo citocina designa um conjunto de proteínas produzidas por diferentes tipos celulares, que participam dos mecanismos de resposta imune inata e adaptativa.

As citocinas mediadores e reguladoras da imunidade inata são: Fator de Necrose Tumoral (TNF), Interleucina 1 (IL-1), quimiocinas, Interleucina-12 (IL-12), Interferons (IFN's), Interleucina 10 (IL10), Interleucina-6 (IL-6), Interleucina-15 (IL-15) e Interleucina-18 (IL-18). As citocinas mediadoras e reguladoras da resposta imune específica são produzidas especialmente pelas subpopulações de células $\mathrm{T}$ auxiliares, que expressam o receptor $\mathrm{CD}^{+}{ }^{+}$. As células Th1 estão relacionadas ao desencadeamento da resposta imune celular e secretam principalmente IL-2, TNF- $\alpha$ e IFN- $\gamma$. As células Th2 estão relacionadas com a produção de anticorpos e produzem principalmente IL-3, IL-4, IL-5 e IL-10 (Tizard, 2008).
Diferentes tipos de citocinas pró-inflamatórias foram detectados no colostro bovino, com destaque para IL-1 $\beta$, IL-6 e TNF- $\alpha$ e IFN- $\gamma$. A concentração dessas citocinas é significantemente maior na primeira secreção láctea pós-parto em relação ao leite (Quadro 2) (Hagiwara et al., 2000).

A expressão gênica de citocinas foi dectada nas células do colostro, sugerindo que a produção dessas substâncias ocorre localmente na glândula mamária (Hagiwara et al., 2000). Além dos leucócitos, as células epiteliais mamárias produzem IL-1 $\beta$, IL-6 e IL-8. A hipótese de que estas células produzem citocinas foi reforçada no estudo realizado por Schecaira et al. (2014), no qual foram adotados três grupos experimentais compostos por bezerros que ingeriram colostro fresco, colostro congelado sem células viáveis e leite. Estes autores verificaram maiores concentrações das citocinas IL-1 $\beta$, IL-6 e TNF- $\alpha$ e IFN- $\gamma$ no soro dos bezerros que receberam o colostro fresco com células viáveis em relação às concentrações indetectáveis no soro dos animais que ingeriram colostro congelado ou leite.

Os bezerros recém-nascidos não apresentam concentrações detectáveis de citocinas séricas imediatamente após o nascimento (Yamanaka et al., 2003). Após a ingestão do colostro, a concentração de citocinas IL-1 $\beta$, IL-1ra, IL-6 e TNF- $\alpha$ e IFN- $\gamma$ atinge o seu pico máximo entre 12 e 24 horas de vida, com queda gradual nos momentos subsequentes até atingir níveis indetectáveis ao redor de 28 dias de vida (Yamanaka et al., 2003). Os efeitos das citocinas derivadas do colostro sobre o sistema imune dos recém-nascidos são pouco conhecidos, entretanto, Hagiwara et al. (2001) demonstraram que a IL-1 $\beta$ promove ativação de linfócitos e neutrófilos em bezerros.

Gonzalez et al. (2013) vacinaram vacas com duas vacinas experimentais contendo o rotavírus ou apenas a proteína VP6. Nesta pesquisa, as células mononucleares do colostro foram isoladas e avaliadas quanto à expressão das citocinas IL4, IL-6, IL-10, IL-12, IFN- $\gamma$ e IFN- $\alpha$. Estes autores verificaram diferentes perfis para a expressão de citocinas de acordo com o tipo de vacina. Assim, concluíram que as células do colostro podem ser ativadas por diferentes estímulos no período préparto e desencadear a produção de citocinas que atuarão na resposta imune dos recém-nascidos. 
Quadro 2 - Concentração de citocinas pró-inflamatórias no colostro bovino

\begin{tabular}{|c|cccccc|}
\hline & \multicolumn{3}{|c}{ Dias pós-parto } & \multicolumn{3}{c|}{ Fases da Lactação } \\
\cline { 2 - 7 } Citocinas & $\mathbf{0}$ & $\mathbf{3}$ & $\mathbf{5}$ & Início & Meio & Final \\
\hline II 1 ß & 844,24 & 239,77 & 11,17 & 3,43 & 0,49 & 3,17 \\
II-6 & 77,08 & 14,10 & 1,23 & 0,22 & 0,06 & 0,15 \\
TNF-a & 926,55 & 303,53 & 16,74 & 4,58 & 2,25 & 3,31 \\
IFN- $\gamma$ & 261,37 & 71,06 & 3,82 & 0,00 & 0,00 & 0,21 \\
\hline
\end{tabular}

Fonte: Hagiwara et al., 2000.

\section{Bactérias comensais/simbióticas: o papel do colostro como um probiótico natural}

O desenvolvimento das técnicas de biologia molecular permitiu a realização de estudos metagenômicos com o objetivo de desvendar a complexa relação entre microrganismos e hospedeiro, previamente limitada às técnicas tradicionais de cultivo, no qual apenas $25 \%$ das bactérias do ecossistema poderiam ser detectadas. Estudos atuais demonstraram que o trato gastrintestinal é o local que alberga o maior número e diversidade de microrganismos bacterianos (1.014), que desempenham diferentes funções no desenvolvimento do sistema imune dos recémnascidos, além de sua participação no metabolismo energético do hospedeiro por meio da fermentação de carboidratos e biosíntese de cofatores e vitaminas K e B12 (Matamoros et al., 2013).

A riqueza (abundância), diversidade e estabilidade da população bacteriana no intestino são indicativos de saúde. Em contrapartida, a redução na diversidade das bactérias intestinais está associada ao maior risco de alergias, enterites necrosantes e doença de Crohn's (Hollister et al., 2014; Manichanh et al., 2006).

A colonização bacteriana do intestino é um processo complexo. Ainda não é consensual, mas alguns pesquisadores acreditam que esse evento inicia-se em pequena escala durante o período fetal, devido à detecção de material genético e/ ou bactéria viável no líquido amniótico, mecônio e cordão umbilical. A intensificação no processo de colonização intestinal ocorre a partir do nascimento (Martin et al., 2012).
Em humanos, a similaridade entre a microbiota da secreção mamária e fezes tem sugerido a transferência vertical de bactérias durante o processo de amamentação. Staphylococcus, Streptococcus e Enterobacteriaceae são os principais grupos de aeróbios identificados no leite materno e fezes de recém-nascidos humanos, além dos anaeróbios Bifidobacterium e Lactobacilllus (Albesharat et al., 2011; Jimenez et al., 2008; Martin et al., 2003; Martin et al., 2012).

0 processo de colonização pós-natal requer mecanismos imunes que diferenciem os microrganismos comensais/simbióticos dos patobióticos. O sucesso simultâneo entre dois processos tão divergentes requer mecanismos de controle muito sofisticados, que não são compatíveis com o sistema imune inexperiente dos recém-nascidos. As diferenças entre a composição da microbiota intestinal e susceptibilidade dos bebês aleitados com sucedâneo, em relação ao leite materno, sugerem que o elemento regulador do processo de colonização e modulação da resposta imune pode ser adquirido pelo processo de amamentação (Perez et al., 2007).

Em geral, as bactérias do intestino exercem atividade antibacteriana e imunomoduladora por meio de distintos mecanismos como a produção de ambiente fisiologicamente restrito ( $\mathrm{pH}$ e pressão 02), produção de substâncias antimicrobianas, formação da barreira intestinal pela produção de mucina, reduzindo a permeabilidade do epitélio, competição por sítios de ligação, e estimulação da tolerância imunológica aos microorganismos comensais/simbióticos (Fernández et al., 2013). 


\section{Conclusão}

O colostro é rico em fatores imunomodulatórios que, apesar de possuírem funções aparentemente distintas, atuam em conjunto na proteção dos recémnascidos. As pesquisas sobre a função dos demais fatores do colostro, além das imunoglobulinas, são muito promissoras para a elaboração de estratégias futuras que colaborem com a proteção direta ou indireta dos bezerros nos primeiros meses de vida.

\section{Referências}

Albesharat R, Ehrmann MA, Korakli M, Yazaji S, Vogel RF. Phenotypic and genotypic analyses of lactic acid bacteria in local fermented food, breast milk and faeces of mothers and their babies. Syst Appl Microbiol. 2011;34(2):148-55.

Aldridge BM, McGuirk SM, Lunn DP. Effect of colostral ingestion on immunoglobulin-positive cells in calves. Veterinary Immunology and Immunopathology. Vet Immunol Immunopathol. 1998 Mar 18;62(1):51-64..

Barrington GM, Parish SM. Bovine Neonatal Immunology. Vet Clin North Am Food Anim Pract. 2001;17(3):463-76.

Baumrucker CR, Bruckmaier RM. Colostrogenesis: IgG1 transcytosis mechanisms. J Mammary Gland Biol Neoplasia. 2014;19(1):103-17.

Chase CCL, Hurley DJ, Reber AJ. Neonatal immune development in the calf and its impact on vaccine response. Vet Clin North Am Food Anim Pract. 2008;24(1):87-104.

Chase CCL, Thakur N, Darweesh MF, Morarie-Kane SE, Rajput MK. Immune response to bovine viral diarrhea viruslooking at newly defined targets. Anim Health Res Rev. 2015;16(1):4-14.

Costa JFDR, Novo SM, Baccili CC, Sobreira NM, Hurley DJ, Gomes V. Innate immune response in neonate Holstein heifer calves fed fresh or frozen colostrum. Res Vet Sci. 2017;115:54-60.

Donovan DC, Reber AJ, Gabbard JD, Aceves-Avila M, Galland KL, Holbert KA, et al. Effect of maternal cells transferred with colostrum on cellular responses to pathogen antigens in neonatal calves. Am J Vet Res. 2007;68(7):778-82.

Fernández L, Langa S, Martín V, Maldonado A, Jiménez E, Martín R, et al. The human milk microbiota: origin and potential roles in health and disease. Pharmacol Res. 2013;69(1):1-10.

Gomes V. Fatores imunológicos do colostro bovino: células, imunoglobulinas e atividade bactericida dos fagócitos para a Escherichia coli enterotoxigênica [tese]. São Paulo: Universidade de São Paulo; 2008. 106 p.

Gomes V, Madureira KM, Dellalibera AMMP, Alves M, Baptistella F, Benesi FJ. Dinâmica da celularidade do colostro de vacas holandesas no pós-parto imediato. Arq Bras Med Vet. Zootec. 2011;63(5):1047-53.

Gomes V, Madureira KM, Soriano S, Pontes GN, Silva BT, Dellalibera AMP, et al. Release of hydrogen peroxide by phagocytes from bovine colostrum in the peripartum period. Acta Vet Brno. 2014;83(3):181-5.

Gonzalez DD, Rimondi A, Aguirreburualde MP, Mozgovoj M, Bellido D, Wigdorovitz A, et al. Quantitation of cytokine gene expression by real time PCR in bovine milk and colostrum cells from cows immunized with a bovine rotavirus VP6 experimental vaccine. Res Vet Sci. 2013;95(2):703-8.

Gonzalez DD, Dus Santos MJ. Bovine colostral cells - the often forgotten component of colostrum. J Am Vet Med Assoc. 2017;250(9):998-1005.

Hagiwara SI, KawaI K, Anri A, Nagahata H. Lactoferrin concentrations in milk from normal and subclinical mastitic cows. J Vet Med Sci. 2003;65(3):319-23.

Hagiwara K, Kataoka S, Yamanaka H, Kirisawa R, Iwai H. Detection of cytokines in bovine colostrum. Vet Immunol Immunopathol. 2000;76(3-4):183-90.

Hollister EB, Gao C, Versalovic J. Compositional and functional features of the gastrointestinal microbiome and their effects on human health. Gastroenterology. 2014;146(6):1449-58.

Jiménez E, Delgado S, Fernández L, García N, Albújar M, 
Gómez A, et al. Assessment of the bacterial diversity of human colostrum and screening of staphylococcal and enterococcal populations for potential virulence factors. Res Microbiol. 2008;159(9-10):595-601.

Langel SN, Wark WA, Garst SN, James RE, McGilliard ML, Petersson-Wolfe CS, et al. Effect of feeding whole compared with cell-free colostrum on calf immune status: The neonatal period. J Dairy Sci. 2015;98(6):3729-40.

Liebler-Tenorio EM, Riedel-Caspari G, Pohlenz JF. Uptake of colostral leukocytes in the intestinal tract of newborn calves. Vet Immunol Immunopathol. 2002;85(1-2):33-40.

Mandyla H, Xanthou M, Marvelias C, Baum D, Matsaniotis N. Antibody dependent cytotoxicity of humam colostrum phagocytes. Pediatr Res. 1982;16(12):995-9.

Manichanh C, Rigottier-Gois L, Bonnaud E, Gloux K, Pelletier E, Frangeul L, et al. Reduced diversity of faecal microbiota in Crohn's disease revealed by a metagenomic approach. Gut. 2006;55(2):205-11.

Martin R, Langa S, Reviriego C, Jiménez E, Marín ML, Xaus J, et al. Human milk is a source of lactic acid bacteria for the infant gut. J Pediatr. 2003;143(6):754-8.

Martín V, Maldonado-Barragán A, Moles L, RodriguezBaños M, Campo RD, Fernández L, et al. Sharing of bacterial strains between breast milk and infants feces. J Hum Lact. 2012;28(1):36-44.

Matamoros S, Gras-Leguen C, Le Vacon F, Potel G, de La Cochetiere MF. Development of intestinal microbiota in infants and its impact on health. Trends Microbiol. 2013;21(4):167-73.

Morein B, Blomqvist G, Hu K. Immune responsiveness in the neonatal period. J Comp Pathol. 2007;137(Supl 1):S27-31.

Murphy K, Travers P, Walport M. Imunobiologia de Janeway. $7^{\circ}$ ed. Porto Alegre: Artmed; 2010.

Novo SMF, Costa JFDR, Baccili CC, Sobreira NM, Silva BT, Oliveira PL, et al. Effect of maternal cells transferred with colostrum on the health of neonate calves. Res Vet Sci. 2017a;112:97-104.
Novo SMF, Costa JFDR, Baccili CC, Sobreira NM, Maia M, Bilma S, et al. Specific Immune Response in Neonate Holstein Heifer Calves Fed Fresh or Frozen Colostrum. In prelo: Pesqui Vet Bras. 2017b.

Perez PF, Doré J, Leclerc M, Levenez F, Benyacoub J, Serrant P, et al. Bacterial imprinting of the neonatal immune system: lessons from maternal cells? Pediatrics. 2007;119(3):e724-32.

Reber AJ, Donovan DC, Gabbard J, Galland K, AcevesAvila M, Holbert KA, et al. Transfer of maternal colostral leukocytes promotes development of the neonatal immune system Part I. Effects on monocyte lineage cells. Vet Immunol Immunopathol. 2008a;123(3-4):186-96.

Reber AJ, Donovan DC, Gabbard J, Galland K, AcevesAvila M, Holbert KA, et al. Transfer of maternal colostral leukocytes promotes development of the neonatal immune system Part II. Effects on neonatal lymphocytes. Vet Immunol Immunopathol. 2008b;123(3-4):305-13.

Reber AJ, Lockwood A, Hippen AR, Hurley DJ. Colostrum induced phenotypic and trafficking changes in maternal mononuclear cells in a peripheral blood leukocyte model for study of leukocyte transfer to the neonatal calf. Vet Immunol Immunopathol. 2006;109(1-2):139-50.

Riedel-Caspari G. The influence of colostral leukocytes on the course of an experimental Escherichia coli infection and serum antibodies in neonatal calves. Vet Immunol Immunopathol. 1993;35(3-4):275-88.

Riedel-Caspari G, Schmidt FW. The influence of colostral leukocytes on the immune system of the neonatal calf. I Effects on lymphocyte responses. Dtsch Tierarztl Wochenschr. 1991;98(3):102-7.

Riedel-Caspari G, Schmidt FW. The influence of colostral leukocytes on the immune system of the neonatal calf. II Effects on passive and active immunization. Dtsch Tierarztl Wochenschr. 1991;98(5):190-4.

Sacks G, Sargent I, Redman C. An innate view of human pregnancy. Immunology today. Immunol Today. 1999;20(3):114-8.

Shecaira CL, Madureira KM, Gomes V, Seino CH, Santos 
RBD, Bombardelli JA, et al. Evaluation of the transfer of cytokines to the blood of neonates by colostrum ingestion of Holstein females. Pesq Vet Bras. 2014;34(12):1271-5.

Silva CPC. Imunidade inata no sangue e secreção mamária de vacas Holandesas no período periparto [dissertação]. São Paulo: Universidade de São Paulo; 2014. 142 p.

Sheldrake RF, Husband AJ. Intestinal uptake of intact maternal lymphocytes by neonatal rats and lambs. Res Vet Sci. 1985;39(1):10-5.

Tizard IR. Imunologia veterinária: uma introdução. $8^{\circ}$ ed. São Paulo: Roca; 2008.

Tornquist SJ, RIGAS J. Interpretation of ruminant leukocyte. In: Schalm OW. Veterinary Hematology. $2^{\circ}$ ed. Philadelphia, PA: Lea and Febiger; 2010. p. 307-12.

Tuboly S, Bernáth S, Glávits R, Kovács A, Megyeri Z. Intestinal absorption of colostral lymphocytes in newborn lambs and their role in the development of immune status. Acta Vet Hung. 1995;43(1):105-15.

Tuboly S, Bernáth S, Glávits R, Medveczky I. Intestinal absorption of colostral lymphoid cells in newborn piglets. Vet Immunol Immunopathol. 1988;20(1):75-85.

Wegmann TG, Lin H, Guilbert L, Mosmann TR. Bidirectional cytokine interactions in the maternal-fetal relationship: is successful pregnancy a TH2 phenomenon? Immunol Today. 1993;14(7):353-6..

Williams PP. Immunomodulating effects of intestinal absorbed maternal colostral leukocytes by neonatal pigs. Can J Vet Res. 1993;57(1):1-8..

Windeyer MC, Leslie KE, Godden SM, Hodgins DC, Lissemore KD, LeBlanc SJ. Factors associated with morbidity, mortality, and growth of dairy heifer calves up to 3 months of age. Prev Vet Med. 2014;113(2):231-40.

Yamanaka H, Hagiwara K, Kirisawa R, Iwai H. Proinflammatory Cytokines in Bovine Colostrum Potentiate the Mitogenic Response of Peripheral Blood Mononuclear Cells from Newborn Calves through IL-2 and CD25 Expression. Microbiol Immunol. 2003;47(6):461-8. 